\title{
The Effects of Water Exchange Rate and Density on Yield of the Walking Catfish, Clarias fuscus
}

\author{
JAMES S. DIANA ${ }^{1}$ and ARLO W. FAST ${ }^{2}$ \\ ${ }^{1}$ School of Natural Resources and Center for Great Lakes and Aquatic Sciences, University of \\ Michigan, Ann Arbor, MI 48109 (U.S.A.) \\ ${ }^{2}$ Mariculture Research and Training Center, Hawaii Institute of Marine Biology, University of \\ Hawaii, Kaneohe, HI (U.S.A.)
}

(Accepted 8 November 1988)

\section{ABSTRACT}

Diana, J.S. and Fast, A.W., 1989. The effects of water exchange rate and density on yield of the walking catfish, Clarias fuscus. Aquaculture, 78: 267-276.

High stocking densities ( $600 \mathrm{fish} / \mathrm{m}^{3}$ ) of walking catfish resulted in slightly higher mortality rate, no difference in growth rate, and a much higher yield than low density stocking (300 fish/ $\left.\mathrm{m}^{3}\right)$. Water flow rate $(10,5$, or 2.5 turnovers/day, turnover here is one diluted replacement volume) had no effect on survival, growth, or yield. Fish were grown out from an initial weight of 5.4 $\mathrm{g}$ for 90 days, and most mortality occurred early in the cycle when the fish weighed $<26 \mathrm{~g}$. Growth was also high initially and declined with time. Dissolved oxygen did not differ between tanks of different density, but was altered by flow rate. Water supply parameters, such as short-term BOD, strongly affected dissolved oxygen content at all flow rates. Ammonia concentrations increased with density and decreased with increased flow rate. Mortality rate of all fish was strongly size dependent, and mortality of small fish was correlated with short-term BOD.

\section{INTRODUCTION}

Yield of Clarias spp. under culture can approach $100000 \mathrm{~kg} / \mathrm{ha} \mathrm{year}^{-1}$ (Bar- $^{-}$ dach et al., 1972). Such yields are among the highest known for standing water systems. Clarias, a freshwater genus, often is stocked at extremely high densities, as it tolerates anoxic water by using atmospheric air for respiration (Hogendoorn, 1979). Earthen ponds or recirculating concrete tanks commonly are used in Thailand, and fish are either fed with trash fish or commercial feed. Yields in earthen ponds are generally lower than those in concrete tanks (Tarnchalanukit et al., 1983). These differences in yield are thought to be due to differences in water quality affecting survival and growth (Tarnchalanukit et al., 1983; Diana et al., 1985).

If improved water quality increases Clarias yield in culture, then factors such 
as water exchange rate and stocking density should also affect yield. Water quality parameters that commonly affect yield in fishes include dissolved oxygen (D.O.) and nitrogen metabolite concentrations (Boyd, 1979). D.O. is not as important for Clarias survival as for other fishes, although it is uncertain whether small fish $(<20 \mathrm{~g})$ can survive in anoxic water (Doudoroff and Shumway, 1970; Tarnchalanukit et al., 1983). Unfortunately, studies of metabolism to date have not included anoxic conditions for fish of this size (Magdid and Babiker, 1975; Jordan, 1976; Munshi et al., 1976; Hogendoorn, 1983).

The purpose of our study was to evaluate the effects of stocking density and water flow rate on the yield, mortality, and growth of Clarias fuscus in recirculating tanks. Our hypothesis was that improved water quality, related to altered stocking density or water flow rate, would increase yield of Clarias. Since growth and survival are often density dependent (Backiel, 1978), the interaction between density and yield may not be solely due to water quality differences. To estimate density effects, trials were set up to provide identical water flow rates per fish at each density. If fish metabolism and food input affect water quality in tanks, then multiples of density and flow conditions should produce similar D.O. and ammonia levels. D.O., ammonia concentration, flow rate, fish number, and fish biomass were measured regularly to quantify changes between and among tanks.

\section{MATERIALS AND METHODS}

The experiment was a $3 \times 2$ factorial design with three water flow rates, two fish densities, and two replicates per treatment. Tests were conducted in 12 tanks at the Mariculture Research and Training Center, Hawaii Institute of Marine Biology, Kaneohe, HI. The tanks (1.2 m diameter, $1.0 \mathrm{~m}$ high) were constructed of PVC walls and concrete floors (area $1.1 \mathrm{~m}^{2}$ ) coated with an asphalt sealant suitable for potable water. Water depths and volumes were maintained at $0.61 \mathrm{~m}$ and $0.72 \mathrm{~m}^{3}$, respectively.

System water was pumped from a 0.25 -ha pond to a supply tank $\left(0.5 \mathrm{~m}^{3}\right)$ which fed each experimental tank by gravity flow. Pond water passed through a 1-m high packed-column aerator before entering the supply tank, thus maintaining dissolved gases in the influent water at air saturation. Water flow rate to each tank was controlled, and water level was maintained by a standpipe. Overflow water was returned to the supply pond. The supply pond contained macrophytes and grass carp, Ctenopharygodon idella. Water quality in the supply pond was conditioned by the biotic communities, as well as inputs from a freshwater stream and rainfall.

On 5 May 1986, Clarias fuscus were stocked 300 or $600 \mathrm{fish} / \mathrm{m}^{3}$ (200 or 400 / $\mathrm{m}^{2}$ ). At stocking, the fish averaged $5.4 \mathrm{~g}$ (range 2-12 g). Normal water flow rates were 10,5 , or 2.5 turnovers per day (actual flow rates were $9.46 \pm 1.34$, $4.65 \pm 0.82$ and $2.46 \pm 0.48$ turnovers per day). A turnover here is considered 
one diluted replacement volume. Due to poor valve control, these flow rates were not stabilized until 19 May. Two replicate tanks were maintained at each flow rate and stocking density. Fish were fed to satiation daily with Rangen dry trout pellets ( $40 \%$ protein). Satiation ration was calculated from data in Tarnchalanukit et al. (1983) for Clarias batrachus. Feeding rates were adjusted weekly after measuring mean weights and total biomass per tank. Tanks were monitored until harvest on 4 August. Water quality measures were continued for an additional week in the tanks following harvest.

D.O., ammonia, water temperature, and flow rate were measured each Monday, then all tanks were drained and fish were weighed and counted. Shortterm biochemical oxygen demand (BOD) was measured weekly (on Friday) from 13 June to termination of the experiment.

D.O. was measured with a YSI meter (air-calibrated daily). Ammonia was measured using the phenate method without preliminary distillation (APHA, 1980 ). Water flow rate was measured directly. Since tank water was often low in oxygen, short-term BOD (henceforth called BOD) was monitored by first aerating water from each tank, placing it in a BOD bottle, and measuring D.O. with a meter, then sealing the bottle and returning it to the experimental tank. Bottles were removed and D.O. determined 1-2 $\mathrm{h}$ later. BOD was calculated as the difference in $\mathrm{O}_{2} \mathrm{l}^{-1} \mathrm{~h}^{-1}$ between these two readings (Boyd, 1979).

Tank water clarity was very low, so fish could not be counted. Rations were added regularly; no evaluation was done to determine whether fish consumed the entire ration. Dead fish sank to the bottom of the tank, and were removed only during weekly draining. Once a week (after sampling the fish population) each tank was drained and scrubbed. No other cleaning or prophylactic treatment was used.

Weekly fish measurements included total biomass in the tank, total number (counted), and mean weight (biomass/number). Mortality rate for each week was calculated as $\left(N_{t}-N_{t-1}\right) / d$, where $N_{t}=$ current number surviving in that tank, $N_{t-1}=$ number in that tank at time $t-1$, and $d=$ number of days. Specific growth rate was calculated as $\left.\left(w_{t}-w_{t-1}\right) /\left(w_{t-1}\right) \cdot d\right)$, where $w_{t}=$ current mean weight and $w_{t-1}=$ mean weight at time $t-1$.

Overall treatment effects were tested for significance by analysis of variance. In addition, factors influencing water condition in each tank were analyzed by stepwise multiple regression. Water quality data collected on Mondays were used as inputs for regression models, except for BOD where Friday measurements were used. Data were analyzed using the MIDAS statistical package (Fox and Guire, 1976). Statements of significance refer to $P<0.05$.

\section{RESULTS}

Higher stocking density resulted in significantly larger yield (all flows combined; $P<0.05$ ) over the 13 -week period (Table 1 ). Yield was the product of 
TABLE 1

Mean of weekly water quality parameters, mortality rates, and growth rates, as well as final yield for each experimental tank. Flow rate in turnovers/day; D.O. in mg/l; BOD in $\mathrm{mg} \mathrm{O}_{2} \mathrm{l}^{-1} \mathrm{~h}^{-1} ; \mathrm{NH}_{3}$ in $\mathrm{mg} / \mathrm{l}$; temperature in ${ }^{\circ} \mathrm{C}$; net yield in $\mathrm{kg}$; mortality in $\% /$ day; growth rate in $\mathrm{g} \cdot \mathrm{g}$ body wt. ${ }^{-1}$ day $^{-1}$

\begin{tabular}{|c|c|c|c|c|c|c|c|c|c|c|c|}
\hline Density & $\begin{array}{l}\text { Flow } \\
\text { rate }\end{array}$ & D.O. ${ }^{a, b}$ & BOD & $\mathrm{NH}_{3}$ & Temp. & $\begin{array}{l}\text { Net } \\
\text { yield }^{a}\end{array}$ & Mort. $^{2}$ & $\begin{array}{l}\text { Growth } \\
\text { rate }\end{array}$ & $\begin{array}{l}\text { D. } 0 . / \mathrm{kg} \\
\text { fish }^{\mathrm{b}}\end{array}$ & $\begin{array}{l}\mathrm{NH}_{3} / \mathrm{kg} \\
\text { fish }^{\mathrm{b}}\end{array}$ & $\begin{array}{l}\text { BOD } / \mathrm{kg} \\
\text { fish }^{\mathrm{b}}\end{array}$ \\
\hline \multirow[t]{6}{*}{$300 / \operatorname{tank}$} & $10^{\mathrm{c}}$ & 2.9 & 0.61 & 590 & 26.3 & 5.8 & 0.8 & 0.18 & 1.02 & 200 & 0.18 \\
\hline & 10 & 3.6 & 0.55 & 420 & 26.3 & 5.7 & 0.9 & 0.17 & 1.39 & 130 & 0.18 \\
\hline & 5 & 1.4 & 0.88 & 740 & 26.3 & 5.3 & 0.9 & 0.17 & 0.56 & 270 & 0.30 \\
\hline & 5 & 1.2 & 1.1 & 840 & 26.3 & 5.2 & 0.9 & 0.17 & 0.50 & 300 & 0.40 \\
\hline & 2.5 & 1.3 & 1.2 & 1010 & 26.3 & 5.6 & 0.9 & 0.16 & 0.65 & 330 & 0.41 \\
\hline & 2.5 & 1.3 & 1.9 & 1210 & 26.3 & 7.6 & 0.5 & 0.16 & 0.49 & 300 & 0.49 \\
\hline \multirow[t]{6}{*}{$600 / \operatorname{tank}$} & 10 & 3.4 & 0.56 & 630 & 26.3 & 10.4 & 0.8 & 0.16 & 0.65 & 110 & 0.08 \\
\hline & 10 & 3.2 & 0.58 & 620 & 26.3 & 8.4 & 0.9 & 0.18 & 0.76 & 140 & 0.11 \\
\hline & 5 & 1.9 & 0.79 & 1030 & 26.3 & 9.8 & 1.0 & 0.16 & 0.42 & 200 & 0.15 \\
\hline & 5 & 1.7 & 1.0 & 910 & 26.3 & 7.5 & 1.2 & 0.18 & 0.40 & 210 & 0.25 \\
\hline & 2.5 & 1.1 & 1.5 & 1340 & 26.3 & 4.8 & 1.6 & 0.16 & 0.38 & 450 & 0.51 \\
\hline & 2.5 & 1.4 & 2.1 & 1470 & 26.3 & 8.5 & 0.8 & 0.15 & 0.37 & 310 & 0.44 \\
\hline Supply & - & 7.5 & - & 393 & 26.3 & - & - & - & - & - & - \\
\hline
\end{tabular}

aSignificant difference between densities ( $P<0.05$, ANOVA).

${ }^{\mathrm{b}}$ Significant difference between flows.

'There were no significant differences for any parameter between replicates of a treatment.

initial stocking density, survival, and individual growth. There was no significant effect of density on growth, but there was a significant increase in mortality with increased density. Average survival over the culture period was $34 \%$ in high density tanks and $46 \%$ in low density tanks. There was no significant effect of flow rate on survival, growth, or yield (Table 1 ).

Growth and mortality rates differed considerably with time. Specific growth rate (combined for density and flow rate treatments) was high early in the experimental cycle and declined continuously as the experiment progressed (Fig. 1). Mortality rate (combined for flow rate treatments) was also high in the early weeks, then declined to a low level after week 7 (Fig. 2). This decline in mortality occurred when mean weight of the fish had reached $26.9 \mathrm{~g}$.

Water quality varied considerably among treatments. D.O. was not different between density treatments, but was significantly different among the flow rate treatments (Table 1). D.O. also varied considerably over time for all flow treatments, although there was no consistent time trend (Fig. 3). D.O. in the tanks was apparently responsive to supply water parameters, as similar trends were observed for all flow rate treatments over time. There were no consistent time trends in D.O. of supply water, but considerable variability existed. 


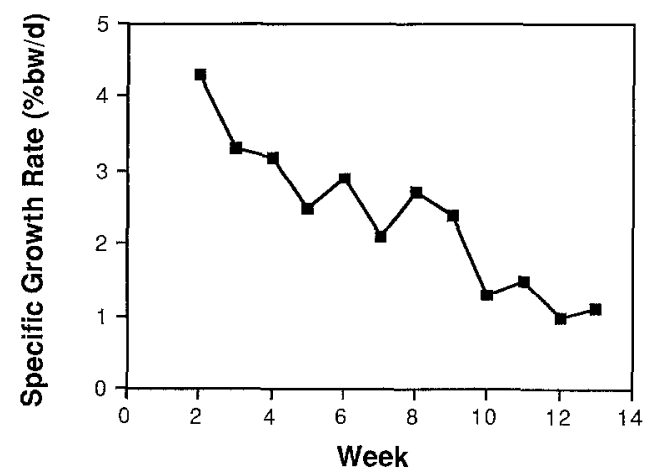

Fig. 1. Time trends in average weekly growth rate (\% body weight/day) of Clarias fuscus during the experiment with stocking densities and water flow rate treatments combined.

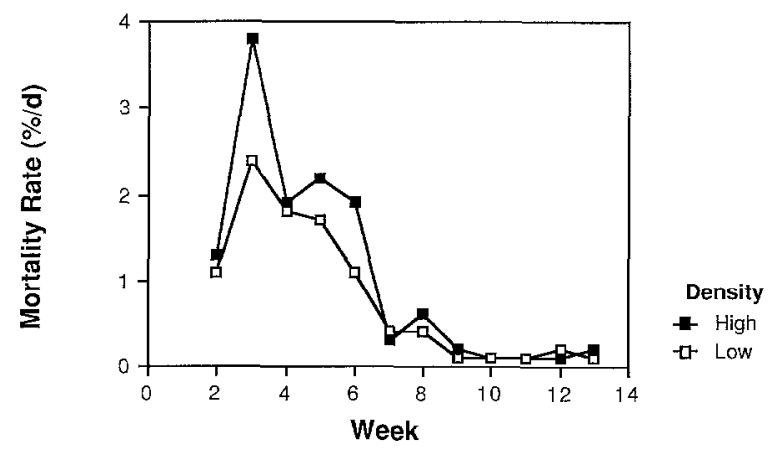

Fig. 2. Time trends in average weekly mortality rate (\%/day) of Clarias fuscus reared for 13 weeks at high and low density $\left(600\right.$ and $\left.300 / \mathrm{m}^{3}\right)$.
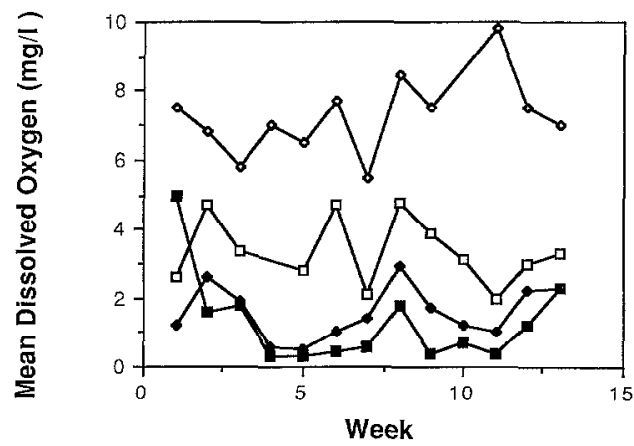

Flow Rate

-ㅁ- High

$\rightarrow$ Medium

$\rightarrow$ Low

- Supply

Fig. 3. Time trends in dissolved oxygen levels of Clarias fuscus rearing tanks at high, medium, and low flow rates, as well as levels in the supply water. 
Ammonia concentrations were significantly higher in high density and low flow treatments (Table 1). Thus, ammonia content more closely followed the original water quality expectations than did D.O. Like D.O., ammonia varied with time, but not in a consistent manner (Fig. 4). However, ammonia levels in high density tanks were always higher than in low density tanks.

Fish mortalities during the cycle resulted in changes in fish density and biomass in each tank. To account for these changes, water quality parameters were also evaluated per $\mathrm{kg}$ of fish (Table 1 ). Flow rate treatments significantly affected D.O. $/ \mathrm{kg}$ fish, $\mathrm{NH}_{3} / \mathrm{kg}$ fish, and $\mathrm{BOD} / \mathrm{kg}$ fish, while density treatments did not have a significant effect. Thus, increased flow rates apparently improved both absolute water quality and relative oxygen supply or metabolite removal per individual fish. However, these changes in water quality did not result in significant effects on growth or survival.

It appears that water quality was dependent on fish density, flow rate, and other factors present in supply water. Under each treatment, an ecosystem developed in each tank with its own oxygen demand and ammonia production; these appeared to be the result of both fish respiration and BOD.

Stepwise multiple regression analyses were done to compare D.O. or ammonia levels with regard to flow rate, water temperature, BOD, fish biomass, fish density, and mean weight of fish. Significant regression equations were found for both D.O. and ammonia. For D.O., the regression equation was fairly predictive $\left(r^{2}=0.67\right)$, and included all factors but mean weight, mortality rate, and density. Most of the variance was explained by water flow rate $\left(r^{2}=0.61\right)$, with about equal contributions from BOD, biomass, and temperature $\left(r^{2} \simeq 0.05\right)$. The regression equation for ammonia was less predictive $\left(r^{2}=0.55\right)$. The major contributor to the variance in ammonia levels was water flow rate

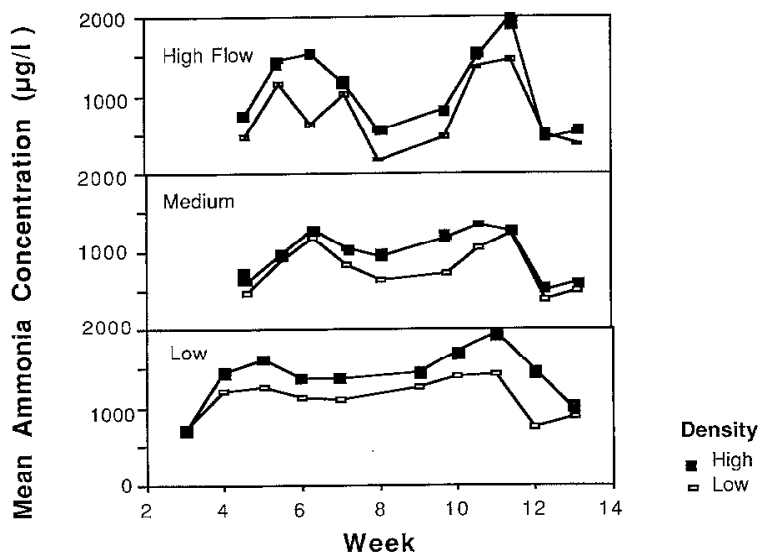

Fig. 4. Time trends in ammonia levels of Clarias fuscus rearing tanks at three flow rates (upper, middle, and lower boxes) and two densities (solid and open symbols). 
$\left(r^{2}=0.43\right)$, with fish density, BOD, and temperature contributing equally $\left(r^{2} \leq 0.08\right)$; mean weight, mortality rate and biomass were not included in the regression equation. Thus, while flow rate and flushing did produce higher oxygen and lower ammonia levels, BOD had more effect on ultimate D.O. than did fish density. Only in the case of ammonia did flow rate and fish density (the test variables) combine to explain most of the variance in water quality.

Following fish harvest, D.O., ammonia, and BOD in all tanks were virtually identical to those of the supply water. This indicates that, although factors such as BOD and flow rate combined to cause treatment differences in water quality, these differences were the result of fish respiration, food utilization, and excretion. It appears that tank water quality is a fairly complex interaction of fish metabolism, influent water quality, and diffusion of gases with the atmosphere.

A stepwise multiple regression analysis was also performed to evaluate interactions between physical, chemical, and biological measurements and daily mortality rate. This regression was significant $\left(r^{2}=0.43\right)$ and included only a constant and the mean weight of fish. Fish density, biomass, and water chemistry variables were excluded by the analysis. The regression equation was: $Y=-0.000397 X+0.021$, where $Y=$ fish weight $(\mathrm{g})$ and $X=$ mortality rate (proportion dying per day). When analysis was limited to fish less than a mean weight of $20 \mathrm{~g}$, the significant regression equation $\left(r^{2}=0.45\right)$ included only BOD: $Y=-0.0043 X+0.028$, where $X=$ BOD and $Y=$ mortality rate.

\section{DISCUSSION}

The hypothesis that increased flow rate or decreased stocking density would increase yield was only partly supported by the data. Density did have a significant effect on yield, but flow rate did not. Density affected mortality but growth did not change significantly with density.

Significant differences in D.O. and ammonia were found among water flow rate treatments, yet there were no significant differences in growth, survival, or yield. D.O. concentrations in tanks were often near zero. Ammonia concentrations reached nearly $2 \mathrm{mg} / 1$, which was approximately four times the concentration in supply water and more than double the lowest tank concentration (Fig. 4). These concentrations are well below lethal levels $\left(\mathrm{LC}_{50}=4.5 \mathrm{~g} /\right.$ 1) or levels that caused growth suppression $(1 \mathrm{~g} / 1)$ for another air-breathing species (Channa striatus, Palanichamy et al., 1985). Either Clarias is not highly sensitive to water quality differences, or the level of differences in our experiment was insufficient to cause differential growth or survival. However, the concentrations were similar to levels toxic to channel catfish, Ictalurus punctatus (3.8 mg/1, Colt and Tchobanoglous, 1978). Ammonia concentrations might become toxic at much higher Clarias stocking densities, or some other limiting factor might become critical first. 
Water flow rate has been shown to be an important parameter in the culture of many fishes, although both oxygen addition and waste removal are required for non-air-breathing fish. High water exchange rates (50-100 turnovers per day) clearly affect carrying capacity of coho salmon, Oncorhynchus kisutch (Westers, 1970). Very low exchange rates (up to 5\% per day) have no effect on water quality of channel catfish ponds (McGee and Boyd, 1983). Intermediate exchange rates ( 1 turnover per day) have been shown to increase yield of Penaeus monodon in ponds (Hiraswa, 1985), but densities in the latter two systems were well below those of our experiments. In the present study, water flow rate, in the range of 2.5-10 turnovers per day, had no effect on yield.

Yield for Clarias fuscus in our system was $9.8 \mathrm{~kg} / \mathrm{m}^{3}$ per 90 days. Comparing our production with a commercial Clarias batrachus system in Thailand indicated that overall yield for the Thai system was much higher for Clarias batrachus $\left(25.4 \mathrm{~kg} / \mathrm{m}^{3}\right.$ per 90 days $)$, due to more rapid growth $(90.2 \mathrm{vs.} 57.7 \mathrm{~g})$ and better survival ( 79.5 vs. $40 \%$ ) (Tarnchalanukit et al., 1983). While these authors did not indicate water temperature, their tanks were likely between 25 and $30^{\circ} \mathrm{C}$. Warmer temperatures in this range could promote faster growth than found in our experiment. The Thai research found no density effects on growth, although survival was variable among densities.

Oxygen levels in our tanks were not solely the result of fish respiration, but rather were a composite of decomposition of uneaten food and feces, fish respiration, BOD, and water flow rate. Ammonia concentrations, however, appeared much more responsive to feed inputs and fish metabolism. Since aerial respiration, which is inversely related to $p \mathrm{O}_{2}$ of the water, may substantially alter oxygen demand by Clarias (Jordan, 1976), this is not surprising.

The question arises as to reasons for the differences between yields from our small tanks and those from larger, commercial systems. Undoubtedly a major difference is the degree of handling. In our experiments, all fish were flushed out the drain, counted, and weighed each week. This handling could produce greater mortality or injury than in commercial systems where fish are not regularly handled. Growth differences could also be species or temperature related.

In Thai culture systems, disease is not treated and tanks are not cleaned. We followed this regime by not treating or removing diseased fish, even though our handling was more intensive than normal culture operations. While this may have reduced yield, it more accurately reflected common Clarias management practices.

Mean weight of fish was the factor most important in predicting mortality. While some of this effect may also have been due to susceptibility to handling stress at a small size, our experience with Clarias fuscus is that fish less than $20 \mathrm{~g}$ have much poorer survival in culture than do fish over $20 \mathrm{~g}$. This may be due in part to low oxygen levels, as small Clarias are obligate water respirers and generally die at D.O. below $5 \mathrm{mg} / \mathrm{l}$ (Doudoroff and Shumway, 1970). The 
multiple regression equation for mortality of fish less than $20 \mathrm{~g}$ included only BOD, which supports this latter suggestion.

Since water quality differences between flow rates did not affect final yield in this or comparable studies (Tarnchalanukit et al., 1983), the reasons for density effects on Clarias survival are unclear. The agent of mortality was not identified, since carcasses were eaten. Open sores were seen on many otherwise healthy individuals. As these sores reached a certain size, they may have attracted other fish to scavenge. At high densities, the increased number of scavenging fish may increase not only the frequency of sores, but also the mortality rate compared with low density treatments.

The results of this study have several implications for fish culture and future research. Apparently, Clarias yields are not improved by increased water turnover rates of more than 2/day. However, higher turnover rates and high water quality may improve early survival of Clarias (to $20 \mathrm{~g}$ in size), and might be used during that phase of culture. Future research should be directed towards determining the proximal causes of mortality in Clarias followed by consideration of simple management solutions to rectify this mortality. Possibly some specific component of water quality, such as unionized ammonia concentration, may be the critical factor.

\section{ACKNOWLEDGEMENTS}

This research was conducted while the senior author was on sabbatical leave. B. Alexander, J. Burgett, R. Cantrell, M. Diana, P. Haine, A. Lesher, P. Olin, D. Ottey, A. Rollins, and M. Young all assisted in the project. Funding was provided partly by the Pond Dynamics/Aquaculture CRSP supported by the Agency for International Development Grant No. DAN-4023-G-SS-2074-00 and partly by U.S.D.A. Section 496 grant "Development of Spawning Induction and Culture Techniques for the Chinese Catfish, Clarias fuscus, in Hawaii". This is contribution 88:28 of the CRSP Aquaculture Project, and contribution 508 of the Center for Great Lakes and Aquatic Sciences, University of Michigan.

\section{REFERENCES}

APHA (American Public Health Association), 1980. Standard Methods for the Examination of Water and Wastewater, 13 th edition. Washington, DC, $1134 \mathrm{pp}$.

Backiel, T., 1978. Some density relationships for fish population parameters. In: S.D. Gerking (Editor), Ecology of Freshwater Fish Production. John Wiley and Sons, New York, NY, pp. 279-302.

Bardach, J.E., Ryther, J.H. and McLarney, W.O., 1972. Aquaculture, the Farming and Husbandry of Freshwater and Marine Organisms. Wiley-Interscience, New York, NY, 868 pp.

Boyd, C.E., 1979. Water Quality in Warmwater Fish Ponds. Auburn University, Agriculture Experiment Station, Auburn, AL, 359 pp. 
Colt, J. and Tchobanoglous, G., 1978. Chronic exposure of channel catfish, Ictalurus punctatis, to ammonia: effects on growth and survival. Aquaculture, 15: 353-372.

Diana, J.S., Chang, W.Y.B., Ottey, D.R. and Chuapoehuk, W., 1985. Production systems for commonly cultured freshwater fishes of southeast Asia. The University of Michigan, Great Lakes and Marine Waters Center, International Programs Report Number 7: 199 pp.

Doudoroff, P. and Shumway, D.L., 1970. Dissolved oxygen requirements of freshwater fishes. FAO Fish. Tech. Paper 86: $291 \mathrm{pp}$.

Fox, D.J. and Guire, K.E., 1976. Documentation for MIDAS. Statistical Research Laboratory, The University of Michigan, Ann Arbor, MI, 203 pp.

Hiraswa, Y., 1985. Economics of shrimp culture in Asia. In: Y. Taki, J.H. Primavera and J.A. Llobrera (Editors), Proceedings of the First International Conference on the Culture of Penaeid Prawns/Shrimps. SEAFDEC Aquaculture Department, Iloilo, The Philippines, pp. 131150.

Hogendoorn, H., 1979. Controlled propagation of the African catfish, Clarias lazera (C. and V.). I. Reproductive biology and field experiments. Aquaculture, 17:323-333.

Hogendoorn, H., 1983. Growth and production of the African catfish, Clarias lazera (C. and V.). III. Bioenergetic relations of body weight and feeding level. Aquaculture, 35: 1-17.

Jordan, J., 1976. The influence of body weight on gas exchange in the air-breathing fish, Clarias batrachus. Comp. Biochem. Physiol. A, 53: 305-310.

Magdid, A.M.A. and Babiker, M.M., 1975. Oxygen consumption and respiratory behavior of three Nile fishes. Hydrobiologia, 46: 359-367.

McGee, M.V. and Boyd, C.E., 1983. Evaluation of the influence of water exchange in channel catfish ponds. Trans. Am. Fish. Soc., 112: 557-560.

Munshi, J.S.D., Sinha, A.L. and Ojha, J., 1976. Oxygen uptake capacity of gills and skin in relation to body weight of the air-breathing siluroid fish, Clarias batrachus (Linn.). Acta Physiol. Acad. Sci. Hung., 48: 23-33.

Palanichamy, S., Arunachalam, S. and Balasubramanian, M.P., 1985. Toxic and sublethal effects of ammonium chloride on food utilization and growth in the air breathing fish Channa striatus. In: R. Day and T.L. Richards (Editors), Proceedings of the Second International Conference on Warm Water Aquaculture - Finfish. Brigham Young University Press, Laie, HI, pp. 481492.

Tarnchalanukit, W., Chuapoehuk, W., Suraniranat, P. and NaNakorn, U., 1983. Pla duk dan culture in circular concrete ponds with water recirculating system. Department of Agriculture, Faculty of Fisheries, Kasetsart University, Bangkok, Thailand, 17 pp.

Westers, H., 1970. Carrying capacity of salmonid hatcheries. Prog. Fish-Cult., 31: 43-46. 